\title{
ELABORAÇÃO E DETERMINAÇÃO FÍSICA, QUÍMICA E MICROBIOLÓGICA DA FARINHA DE TILÁPIA (OREOCHROMIS NILOTICUS) SUBMETIDA A DIFERENTES FONTES DE CALOR
}

\author{
Ana Beatriz Nascimento de Macedo¹, Érica Lima da Silva¹, Marisa de Oliveira \\ Apolinário²
}

${ }^{1}$ Curso de Licenciatura em Ciências Biológicas, Unidade Acadêmica de Biologia e Química, Centro de Educação e Saúde, Universidade Federal de Campina Grande, Cuité-PB, Brasil. 2 Prof ${ }^{a}$ Unidade Acadêmica de Biologia e Química, Centro de Educação e Saúde, Universidade Federal de Campina Grande, Cuité-PB, Brasil.

Email para correspondência: biaah.macedo@hotmail.com

\begin{abstract}
Resumo
Devido ao aumento populacional e a busca por uma alimentação saudável, observa-se que o consumo de pescado, gera uma maior produção de resíduos, os quais são descartados de forma inadequada. $O$ trabalho objetivou-se produzir farinha de resíduos de filetagem da tilápia-do-nilo (Oreochromis niloticus), processadas em diferentes fontes de calor (estufa e forno microondas). A pesquisa foi realizada no Laboratório de Estudos de Peixes e Aquicultura e no de Bioquímica e Biotecnologia de Alimentos, entre novembro de 2018 até junho de 2019. Obteve-se resultados satisfatórios para os teores de $\mathrm{pH}$ e Atividade de Água $(\mathrm{Aw})$, os quais mantiveram-se próximos à neutralidade. Quanto aos teores de Lipídeos os valores aproximaram-se de $8 \%$ para o filé e $22 \%$ para o resíduo, quanto aos valores de Umidade, a farinha obtida por meio do forno microondas esteve dentro dos padrões, e na estufa um pouco elevado. Os valores de Proteínas chegaram a $77 \%$ na estufa e microondas (43\%). As análises microbiológicas apresentaram ausência de bactérias mesófilas. Observou-se a importância de agregar valor ao pescado pelo aproveitamento dos resíduos, benefício ecológico diminuindo a poluição, e por ser um alimento rico em proteína, de custo acessível e de grande aceitação pelo mercado consumidor.
\end{abstract}

Palavras-chave: produção de farinha, análises, pescado, consumo humano.

\begin{abstract}
Due to the population increase and the search for a healthy diet, it is observed that the consumption of fish, generates a greater production of residues, which are improperly disposed of. The work aimed to produce fillet residues flour from Nile tilapia (Oreochromis niloticus), processed in different heat sources (greenhouse and microwave oven). The research was carried out at the Fish and Aquaculture Studies Laboratory and at the Food Biochemistry and Biotechnology Laboratory, from November 2018 to June 2019. Satisfactory results were obtained for the $\mathrm{pH}$
\end{abstract}


and Water Activity (Aw) levels, which remained close to neutrality. As regards of Lipids, fillet values approached $8 \%$, whilst residue's reached $22 \%$, in reference to Moisture values, the flour obtained through the microwave was within the standards, while the greenhouse produced flour values proved to be slightly higher. Greenhouse Protein values reached $77 \%$, whereas microwave's reached $43 \%$. Microbiological analyzes remained within the recommended hygiene standards with no mesophilic bacteria. It was observed the importance of adding value to the fish through the use of residues, ecological benefit reducing pollution, and for being a food rich in protein, with accessible cost and of great acceptance by the consumer market.

Keywords: flour production, analysis, fish, human consumption.

\section{Introdução}

De acordo com a FAO (2016), a demanda mundial por pescado tem aumentado nas últimas décadas, principalmente em função do crescimento populacional e da busca dos consumidores por alimentos mais saudáveis. Segundo Silva-Júnior; Macedo; Apolinário (2019), a aquicultura se apresenta como uma alternativa viável para suprir o mercado consumidor nos próximos anos.

No Brasil e no mundo, a cadeia produtiva do pescado gera grande quantidade de resíduos, considerando-se que $50 \%$ do total produzido são desperdiçados, estima-se que 72,5 milhões de toneladas de resíduos são gerados, por ano, no mundo. Desta forma, a deposição descontrolada dos resíduos da filetagem de pescado no ambiente pode causar vários problemas como a poluição do solo, como também exalar maus odores ou ainda serem carreados pela água das chuvas. (SUCASAS, 2012).

Sabe-se da importância de se agregar valor ao pescado tendo em vista sua riqueza em nutrientes, ser um alimento de proteína saudável e o seu acesso cada vez mais fácil com o produto vendido nos supermercados. Porém, o pescado não é consumido na quantidade esperada, então, buscam-se formas para utilizar todos os benefícios que o pescado possa oferecer enfatizando a produção de derivados com um maior valor agregado e que estimule o consumidor a ter sempre em sua mesa (FOLLMANN, 2013).

Neste sentido, se torna necessária uma forma de direcionar os descartes da filetagem do pescado para que não ocorra poluição e também para sua utilização de forma consciente, fazendo assim com que reaproveitar, especificamente, a carcaça da tilápia seja uma atividade sustentável. Uma forma de trabalhar isso é sabendo aproveitar todas as partes que a tilápia pode 
oferecer, transformando em produtos nos quais os consumidores desejem consumir. Follmann (2013) relata que mais importante do que produzir pescado em grande quantidade para conquistar o mercado consumidor, é a agregação de valor, investir em matérias primas, preço e qualidade do produto.

O aproveitamento dos resíduos gerados por indústrias surge como uma alternativa para tornar o setor mais sustentável ao longo da cadeia produtiva, trazendo melhorias sociais, econômicas e ambientais (GONÇALVES, 2009). Resíduos sólidos gerados na cadeia produtiva da pesca e da aquicultura corresponderam a $20 \%$ do volume de 167,2 milhões de toneladas produzidas no ano de 2014 (FAO, 2016).

Destaca-se que os não comestíveis incluem cabeças, escamas, nadadeiras, peles, vísceras e espinhas. Assim, mesmo com pesquisas sendo desenvolvidas, como as realizadas por Sucasas (2011) e Follmann (2013), para aperfeiçoar o gerenciamento dos resíduos de pescado, ainda ocorre o descarte inadequado destes resíduos no ambiente, ocasionando sérios problemas ambientais

Considerando o crescimento da produção de pescado, a importância socioeconômica da cadeia produtiva, assim como a problemática da geração de resíduos sólidos, a produção de farinha de peixe surge como alternativa para minimizar a geração de resíduos da filetagem do pescado, bem como, agregar valor na fabricação de novos produtos à base de carne mecanicamente separada (CMS).

Desta forma, o trabalho objetivou-se em produzir uma farinha a partir de resíduos de filetagem da tilápia-do-nilo (Oreochromis niloticus), processadas em diferentes fontes de calor (estufa e forno microondas).

\section{Metodologia}

\subsection{Locais de realização dos experimentos}

Uma pesquisa experimental foi realizada no Laboratório de Estudos de Peixes e Aquicultura (LAPEAq) e no de Bioquímica e Biotecnologia de Alimentos (LBBA), conforme a Figura 1, onde foram desenvolvidas as análises físicas e químicas da farinha de peixe, os dois laboratórios estão localizados no Centro 
de Educação e Saúde da Universidade Federal de Campina Grande CES/UFCG durante o período de novembro de 2018 até junho de 2019.

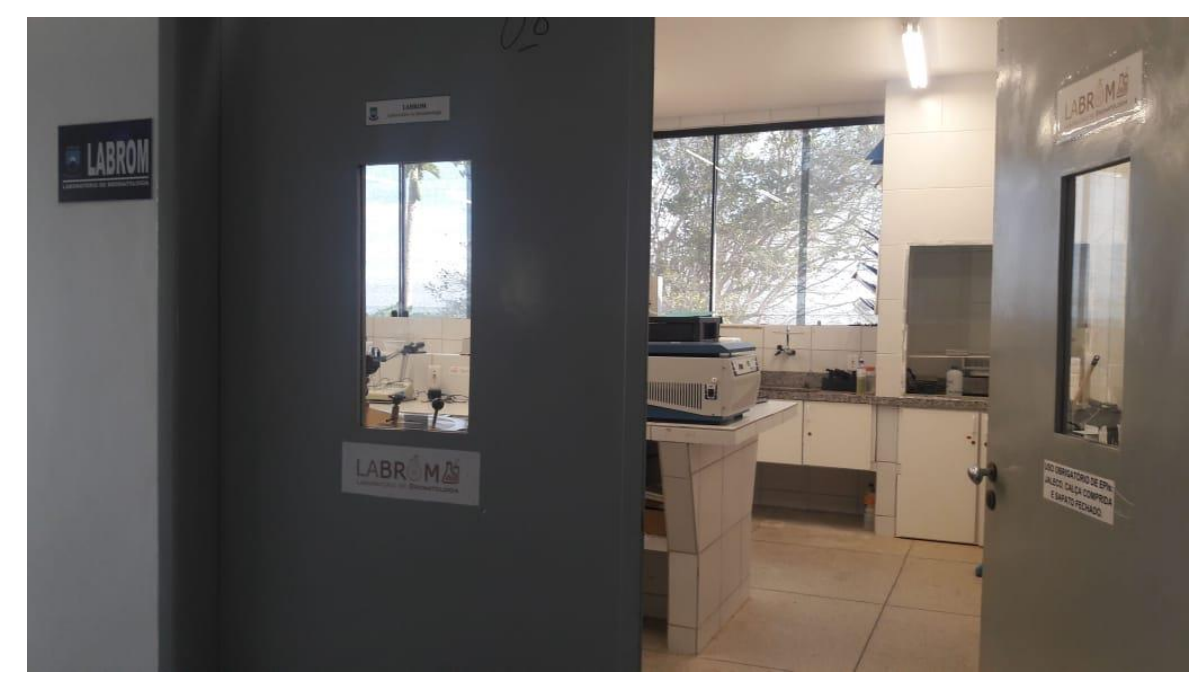

Figura 1 - Laboratório de Bioquímica de Biotecnologia de Alimentos (LBBA) localizado no CES.

Fonte: Arquivo pessoal (2019).

Já as análises microbiológicas foram conduzidas em parceria com 0 Laboratório de Microbiologia e Bioquímica dos Alimentos do Departamento de Nutrição do Centro de Ciências da Saúde (CCS) da Universidade Federal da Paraíba (UFPB), em João Pessoa-PB.

\subsection{Matéria prima}

A matéria prima utilizada foram os resíduos oriundos da filetagem de tilápia (Figura 2) Oreochromis niloticus, aparas de filetagem e a carne mecanicamente separada da carcaça de tilápia.

Foram doados para o projeto $15 \mathrm{~kg}$ de resíduo por um produtor local e comprados $5 \mathrm{~kg}$ de filé de pescado e $4 \mathrm{~kg}$ do pescado comercial. Apesar de não ter sido utilizada toda a matéria prima, foram divididos em 4 bandejas com um total de $500 \mathrm{~g}$ de resíduo em cada uma, isso também foi repetido para a amostra de filé e o filé do pescado comercial. 


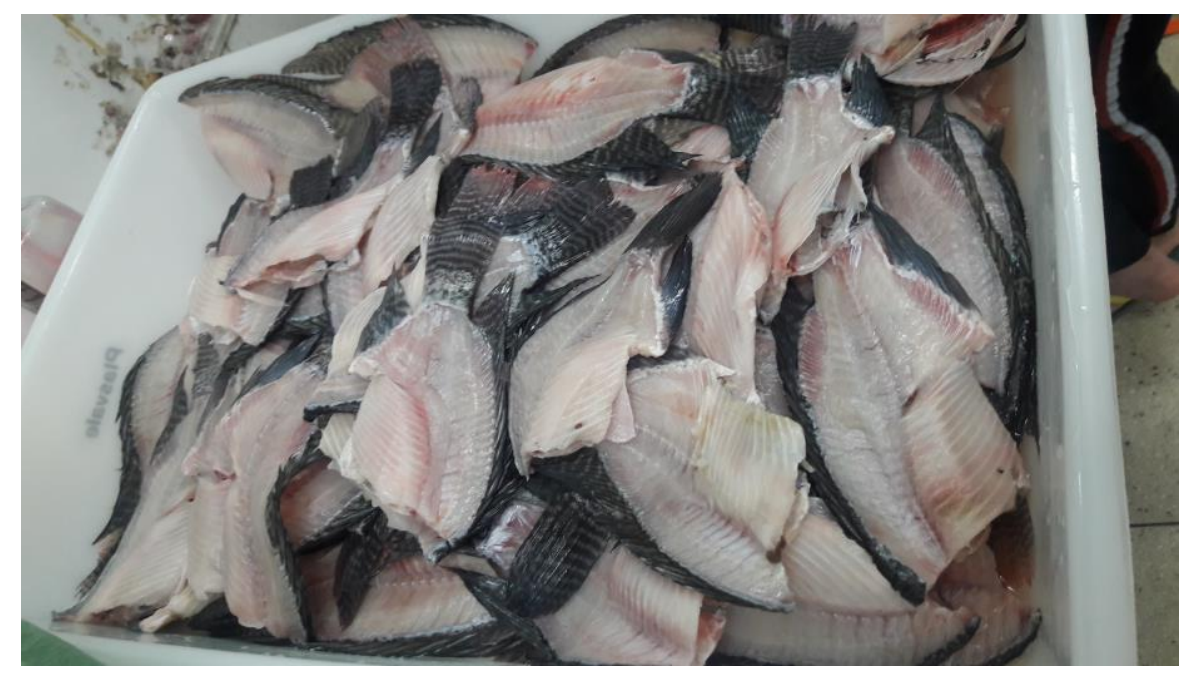

Figura 2 - Matéria prima: Residuos oriundos da filetagem do pescado.

Fonte: Arquivo pessoal (2019)

\subsection{Obtenção da farinha de peixe}

Para a obtenção da farinha e realizadas as comparações, foram utilizadas duas metodologias (Figura 3) e as diferentes matérias primas (Figura 4) para obtenção da farinha, a seguir:

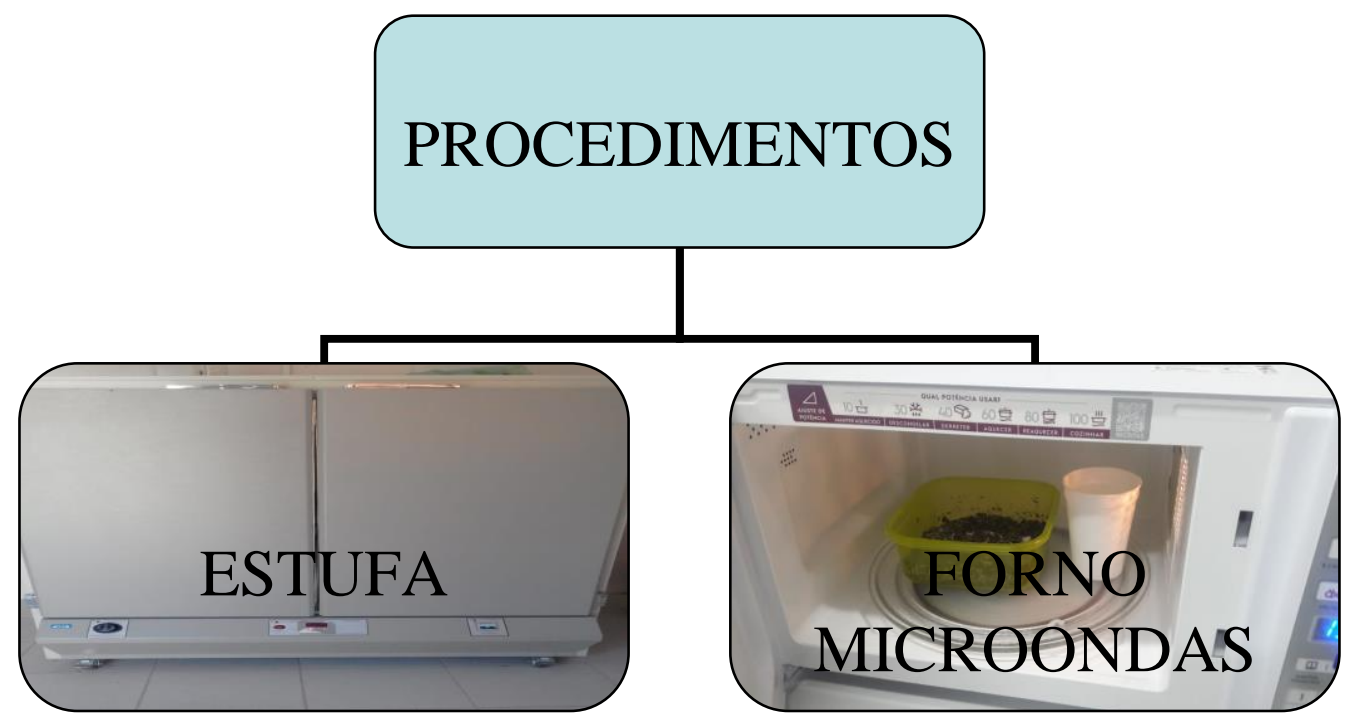

Figura 3 - Esquema de procedimentos aplicados.

Fonte: Arquivo pessoal (2019). 


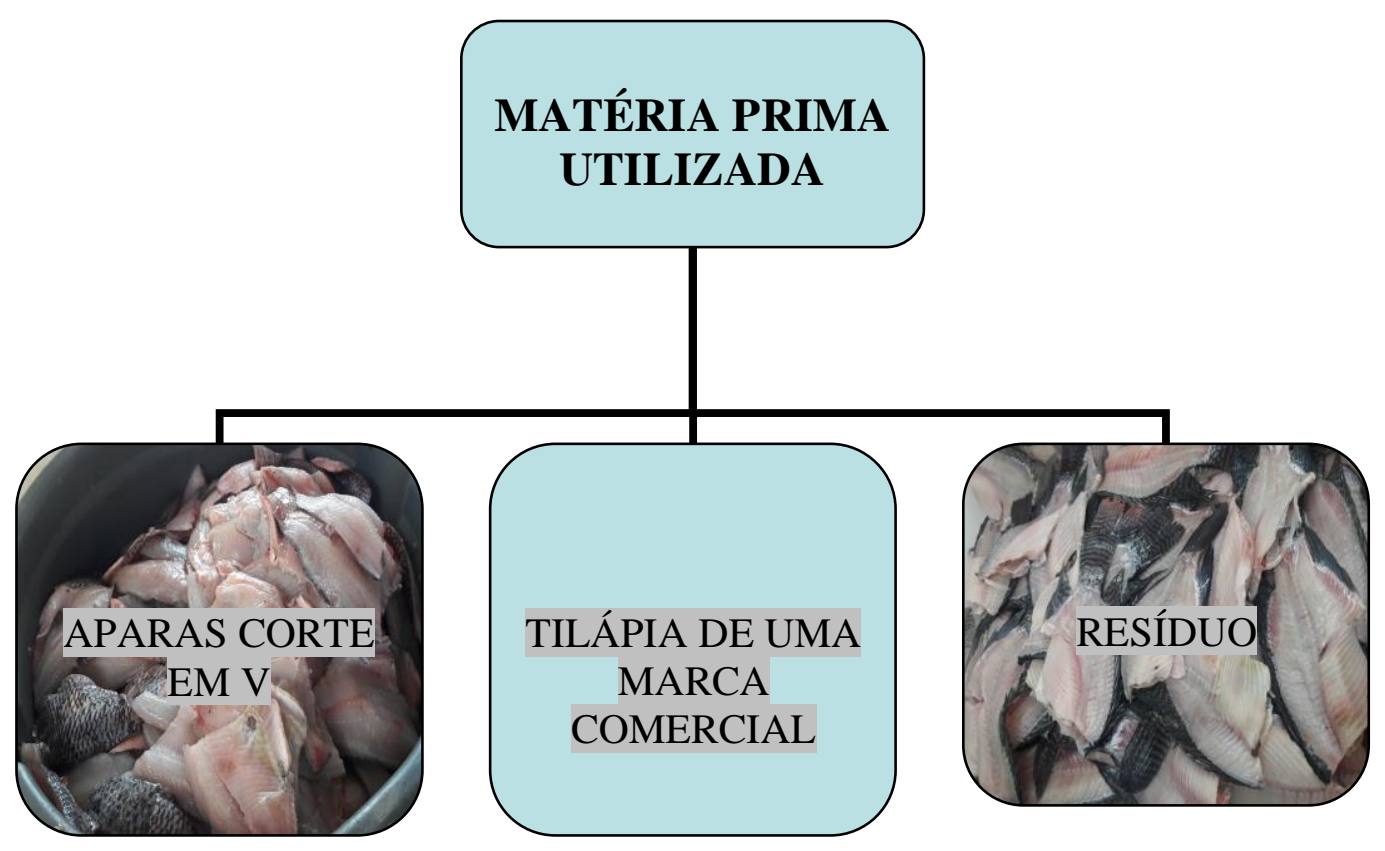

Figura 4 - Esquema dos tipos de matéria prima.

Fonte: Arquivo pessoal (2019)

\subsubsection{Obtenção de farinha de peixe sem extração de óleo em estufa}

Neste método foram utilizados os resíduos da tilápia e a carne mecanicamente separada da carcaça, que depois de adquiridas passaram a ser submetidas à higienização e cortadas em pedaços pequenos e logo em seguida foram congeladas para, posteriormente, seu uso na frabricação da farinha.

No período da fabricação as amostras foram descongeladas em temperatura ambiente e, após a esterilização do ambiente, o material foi submetido à cocção por 30 minutos. Em seguida foram triturados em um liquidificador industrial, para só então erem colocados em uma estufa a $70^{\circ} \mathrm{C}$ durante o período de 24 horas, para se apresentarem secos. Este método foi adaptado de Santos (2016). Assim, após a secagem na estufa o material foi direcionado novamente para o liquidificador, e em seguida triturado, passado na peneira para depois as farinhas serem levadas para suas análises.

\subsubsection{Obtenção de farinha de peixe sem extração de óleo em microondas} Neste método foram utilizados os resíduos da tilápia e a carne mecanicamente separada, que depois de adquiridos foram submetidos à higienização, na 
sequência cortados em pedaços pequenos e congelados para, posteriormente, serem utilizados para fabricar a farinha.

$\mathrm{Na}$ elaboração da farinha os resíduos foram descongelados em temperatura ambiente e após a esterilização do local o material foi submetido à cocção por 30 minutos. Este método foi adaptado de Santos (2016), no qual em seguida os resíduos foram triturados em um liquidificador industrial, para só então serem secos em um forno micro-ondas, no qual foram somados os tempos de secagem totalizando em média 30 minutos para cada amostra. Depois de terem sido secas no forno microondas foram trituradas e peneiradas até o ponto de farinha e direcionadas para as análises, no qual o processo de produção pode ser visto na Figura 5.

\subsection{Análises físicas e químicas}

As análises físicas e químicas foram realizadas no Laboratório de Bioquímica e Biotecnologia de Alimentos (LBBA/CES/UFCG). As amostras das farinhas (Figura 6) foram avaliadas com relação aos teores de umidade (TU), cinzas (TC), nitrogênio (N), Aw, pH, acidez, lipídios e proteínas (Figura 7).

\subsubsection{Análises Microbiológicas}

Foram realizadas análises de contagem de bactérias mesófilas (meio PCA, 30은 $\mathrm{C}, 48 \mathrm{~h}$ ) e contagem de enterobactérias (meio VRBG, 37으 C, 24 h) para as matérias-primas, a fim de analisar a qualidade higiênico-sanitárias. Também foram realizadas análises de contagem de coliformes a $45^{\circ} \mathrm{C}$, contagem de Staphylococcus coagulase positiva e pesquisa de Salmonella sp, seguindo recomendações da ANVISA (2001). 


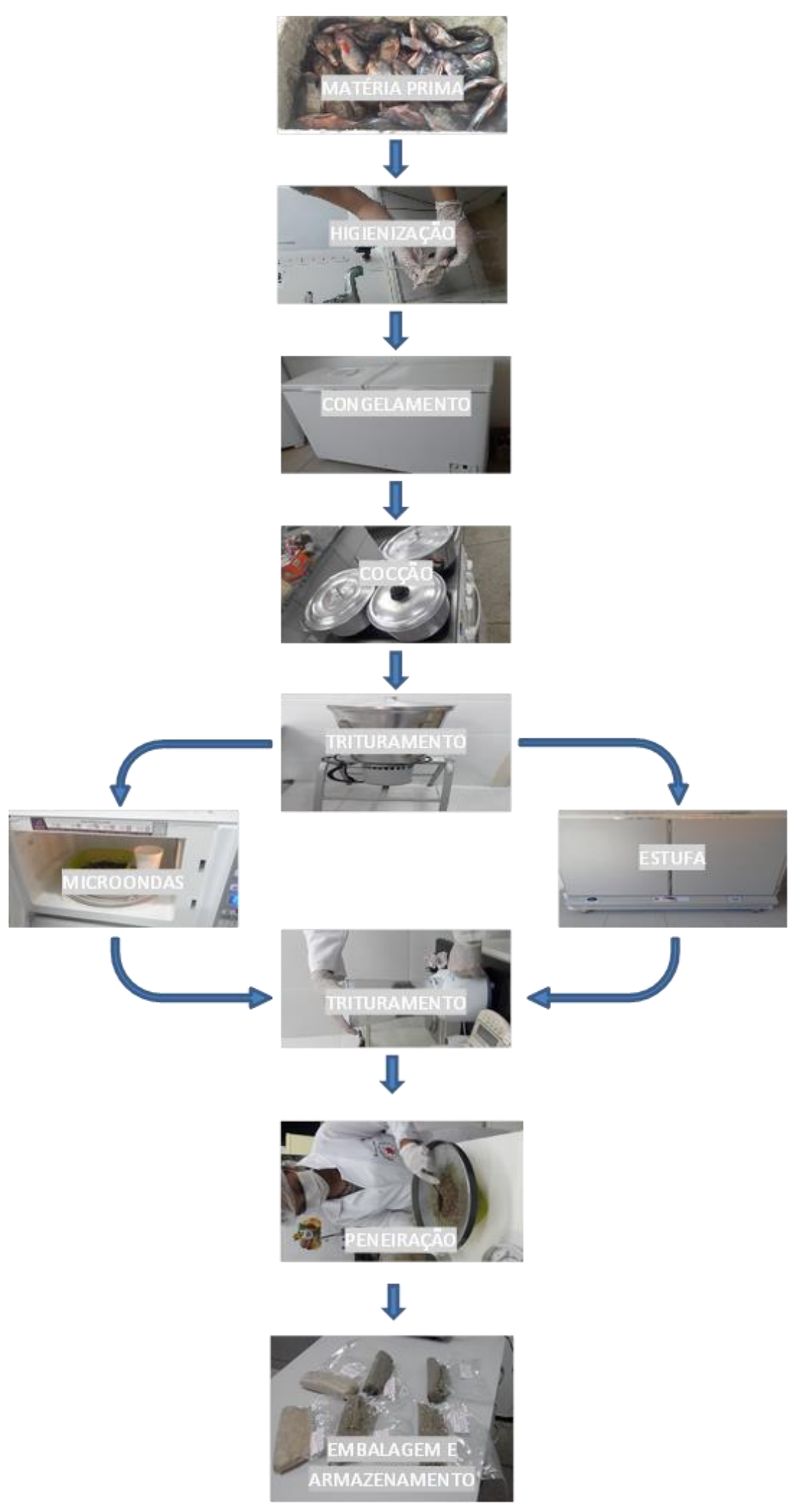

Figura 5- Esquema de representação da metodologia aplicada na pesquisa.

Fonte: Arquivo pessoal (2019) 


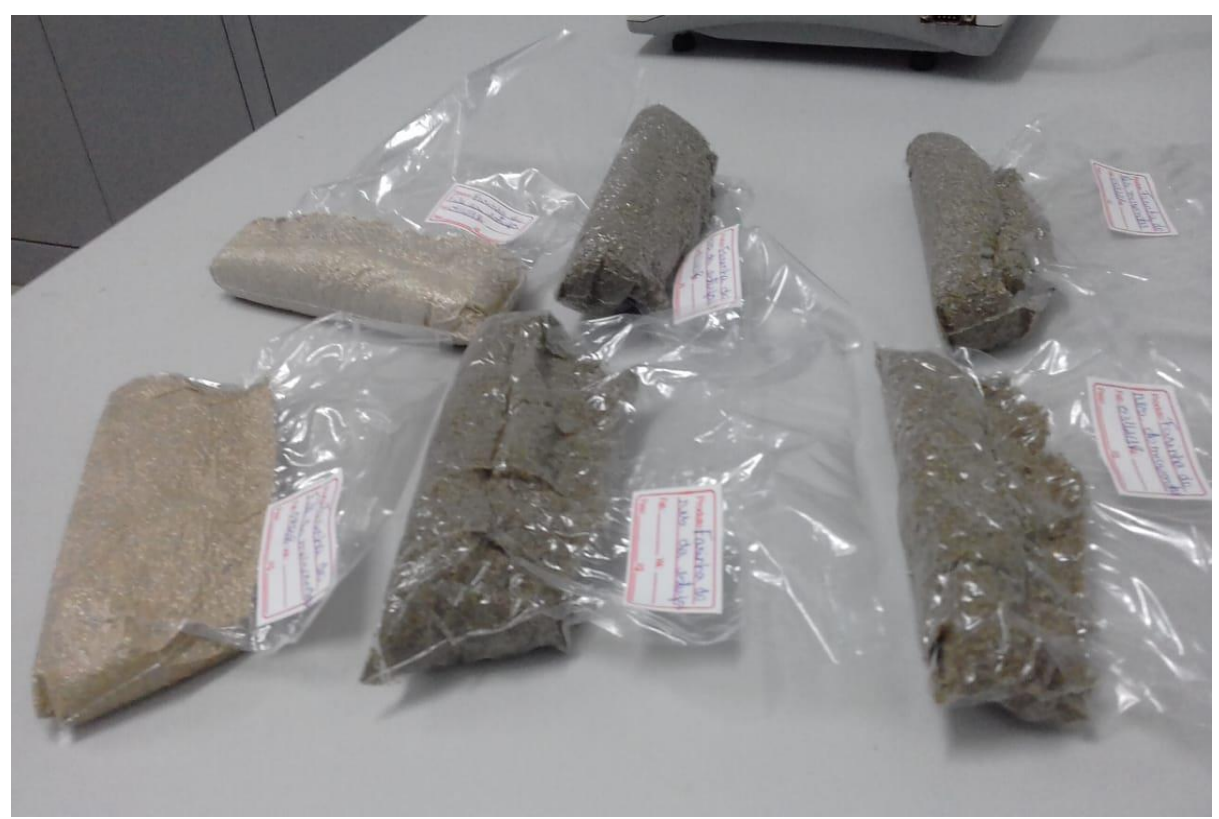

Figura 6 - Farinhas do resíduo e do pescado submetidas à estufa e microondas.

Fonte: Arquivo pessoal (2019).

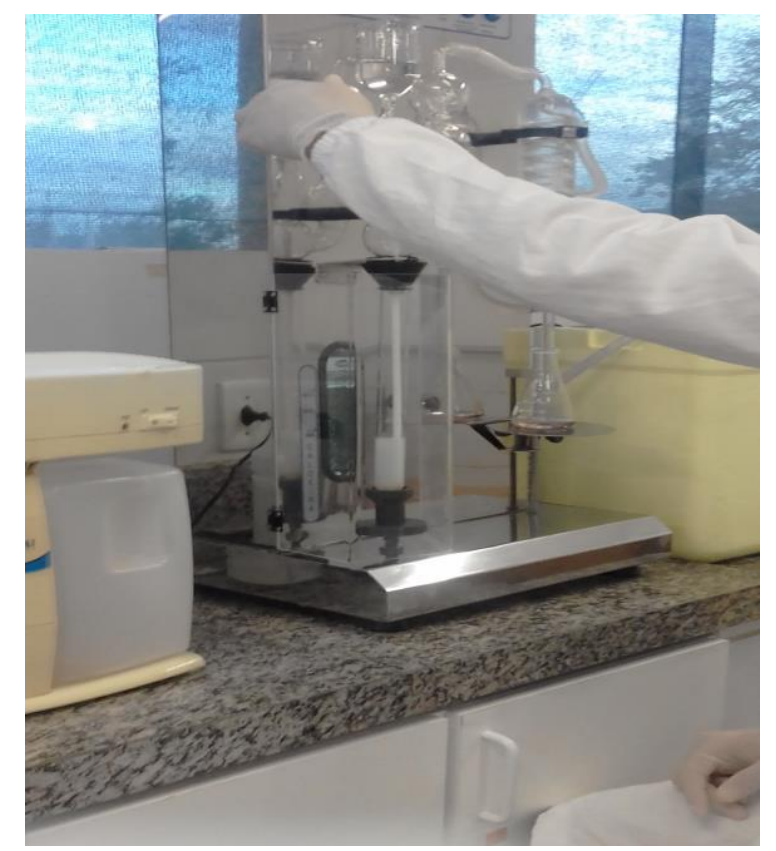

Figura 7 - Realização da destilação no aparelho Kjedahl.

Fonte: Arquivo pessoal (2019).

\subsection{Análise de dados}

Para a análise dos dados as fórmulas utilizadas se basearam no Instituto Adolfo Lutz (2008) foram aplicadas no programa Microsoft Excel e alguns resultados obtidos também passaram pelo programa Sigma stat para uma breve comparação e validação dos resultados. 


\section{Resultados e discussão}

Depois de concluída a etapa da produção das farinhas a partir das matérias primas utilizadas foram realizadas as análises físicas e químicas das amostras para posterior comparação dos dados obtidos (Tabela 1).

\subsection{Teor de Cinzas}

Nas análises de teor de cinzas notou-se que, apenas a farinha do filé de microondas corroborou com os resultados apresentados por Santos (2016).

Os resultados obtidos com as farinhas de estufa se apresentaram maiores que os resultados obtidos com o forno microondas (Tabela 2).

Ao comparar os tratamentos térmicos aplicados à farinha da carne moída da empresa comercial com a farinha do filé da tilápia pôde-se observar que o Forno micro-ondas foi o tratamento mais eficiente, tendo em vista que um menor teor de cinzas aumenta a digestibilidade do produto (OLIVEIRA FILHO; FRACALOSSI, 2006).

No Sigma stat pode-se observar nas amostras que na estufa a farinha do filé apresentou $26,557 \pm 0,218$, e resíduo apresentou $26,807 \pm 0,149$, não tendo diferença significativa entre as amostras, mas as farinhas do filé e resíduo, respectivamente, apresentaram os dados a seguir, $26,8 \pm 0,0202,28,78 \pm 0,912^{*}$, e essas amostras apresentaram diferença estatística, sendo o maior percentual de cinzas na amostra do resíduo do pescado.

\subsection{Umidade}

Observou-se que no forno microondas com a metodologia adotada obteve-se um maior êxito na fabricação da farinha, ao contrário da estufa de circulação de ar que não atendeu aos padrões, com níveis acima de 10\%, corroborando com os dados apresentados por Santos (2016), sendo então, considerado material desidratado.

Após realizar um novo teste com a matéria prima inicial aumentando o tempo do material na estufa, a farinha do resíduo apresentou resultados satisfatórios na quantidade de umidade presente na farinha (4,05\%), ficando abaixo de 10\%, indicado por FAROL (2019). A secagem da farinha se faz essencial para aumentar a qualidade do produto, diminuindo ações de decomposição, umidade e aumentando o tempo de validade (FELLOWS et al., 2006 apud Santos,2016) (Tabela 3). 
Tabela 1 - Resutados das análises físicas e químicas das farinhas de tilápia.

\begin{tabular}{|c|c|c|c|c|c|c|c|}
\hline $\begin{array}{c}\text { Amost } \\
\text { ras }\end{array}$ & $\begin{array}{c}\text { Teor de } \\
\text { Cinzas } \\
(\%)\end{array}$ & $\begin{array}{c}\text { Umidade } \\
\text { (\%) }\end{array}$ & $\begin{array}{c}\text { Acidez } \\
(\%)\end{array}$ & $\begin{array}{c}\text { Lipídeos } \\
(\%)\end{array}$ & $p H$ & $A w$ & $\begin{array}{c}\text { Proteína } \\
\text { (\%) }\end{array}$ \\
\hline FRE & $\begin{array}{l}26,80 \pm 0 \\
15\end{array}$ & $59,36 \pm 0,85$ & $0,73 \pm 0,06$ & $23,10 \pm 0,28$ & $\begin{array}{l}7,23 \pm 0,1 \\
1\end{array}$ & $\begin{array}{l}0,20 \pm 0,0 \\
1\end{array}$ & $\begin{array}{l}43,66 \pm 0,6 \\
3\end{array}$ \\
\hline FRMO & $\begin{array}{l}28,78 \pm 0 \\
91\end{array}$ & $1,32 \pm 0,21$ & $0,68 \pm 0,07$ & $21,04 \pm 0,51$ & $\begin{array}{l}7,26 \pm 0,0 \\
5\end{array}$ & $\begin{array}{l}0,25 \pm 0,0 \\
1\end{array}$ & $\begin{array}{l}43,13 \pm 0,9 \\
3\end{array}$ \\
\hline FFE & $\begin{array}{l}26,55 \pm 0 \\
22\end{array}$ & $72,75 \pm 0,02$ & $2,31 \pm 0,06$ & $8,49 \pm 0,21$ & $6,9 \pm 1,08$ & $\begin{array}{l}0,50 \pm 0,0 \\
0\end{array}$ & $\begin{array}{l}77,77 \pm 0,8 \\
1\end{array}$ \\
\hline FFMO & $\begin{array}{l}3,28 \pm 0,0 \\
2\end{array}$ & $11,80 \pm 0,22$ & $2,43 \pm 0,18$ & $8,65 \pm 0,12$ & $\begin{array}{l}6,73 \pm 0,0 \\
5\end{array}$ & $\begin{array}{l}0,57 \pm 0,0 \\
1\end{array}$ & $77,7 \pm 0,66$ \\
\hline \multirow[t]{2}{*}{ FNE } & $1,22 \pm 0,0$ & $5,20 \pm 0,08$ & $17,89 \pm 2,2$ & $69,92 \pm 56,8$ & $6,74 \pm 0,0$ & $0,51 \pm 0,0$ & $36,37 \pm 5,1$ \\
\hline & 2 & & 8 & 5 & 1 & 0 & 2 \\
\hline \multirow[t]{2}{*}{ FNMO } & $1,21 \pm 0,0$ & $3,15 \pm 0,02$ & $9,49 \pm 1,20$ & $25,03 \pm 0,44$ & $7,18 \pm 0,0$ & $0,30 \pm 0,0$ & $79,93 \pm 0,0$ \\
\hline & 9 & & & & 0 & 1 & 0 \\
\hline
\end{tabular}

Legenda para a Tabela: Farinha de resíduo em estufa (FRE); Farinha de resíduo em forno micro-ondas(FRMO); Farinha de filé em estufa(FFE); Farinha de filé em forno micro-ondas(FFMO); Farinha do produto comercial em estufa(FNE) e Farinha do produto comercial em forno micro-ondas(FNMO).

Fonte: Dados da pesquisa, 2019.

Tabela 2- Comparação do Teor de Cinzas.

\begin{tabular}{c|c|c}
\hline CINZAS (\%) & FE & FMO \\
\hline PRODUTO & $\mathbf{1 , 2 2}$ & $\mathbf{1 , 2 1}$ \\
COMERCIAL & & \\
\hline FILÉ & $\mathbf{2 6 , 5 5}$ & $\mathbf{3 , 2 8}$ \\
\hline RESIDUO & $\mathbf{2 6 , 8 0}$ & $\mathbf{2 8 , 7 8}$ \\
\hline FAROL,2019 & 24 (máx.) & \\
\hline
\end{tabular}

Legenda: Farinha de estufa (FE); Farinha de micro-ondas (FMO) Fonte: Dados da pesquisa, 2019.

Tabela 3 - Comparação do Teor de Umidade.

\begin{tabular}{c|c|c}
\hline UMIDADE (\%) & FE & FMO \\
\hline STEVANATO et al (2007) & 6,0 & \\
\hline SANTOS, 2016 & 77,98 & \\
\hline PRODUTO COMERCIAL & $\mathbf{5 , 2 0}$ & $\mathbf{3 , 1 5}$ \\
\hline FILÉ & $\mathbf{7 2 , 7 5}$ & $\mathbf{1 1 , 8 0}$ \\
\hline RESIDUO & $\mathbf{5 9 , 3 6}$ & $\mathbf{1 , 3 2}$ \\
\hline FAROL,2019 & 10 (máx.) & \\
\hline
\end{tabular}

Legenda: Farinha de estufa (FE); Farinha de micro-ondas (FMO).

Fonte: Dados da pesquisa, 2019 
Ao comparar os valores de umidade da farinha do produto comercial em forno microondas com os de Santos (2016) d Farol (2019) podemos observar que as farinhas obtidas nos dois tratamentos térmicos ficaram dentro dos padrões esperados para a farinha, abaixo de 10\%, corroborando também com os dados de STEVANATO et al. (2007) que foi de $6 \%$.

\subsection{Acidez}

Para os valores de acidez as farinhas de filé e resíduo apresentaram valores abaixo de 10\%, que é o máximo estabelecido por FAROL (2019) (Tabela 4).

Tabela 4- Comparação do Teor de Acidez.

\begin{tabular}{c|c|c}
\hline ACIDEZ (\%) & FE & FMO \\
\hline $\begin{array}{c}\text { PRODUTO } \\
\text { COMERCIAL }\end{array}$ & $\mathbf{1 7 , 8 9}$ & $\mathbf{9 , 4 9}$ \\
\hline FILÉ & $\mathbf{2 , 3 1}$ & $\mathbf{2 , 4 3}$ \\
\hline RESíDUO & $\mathbf{0 , 7 3}$ & $\mathbf{0 , 6 8}$ \\
\hline FAROL,2019 & $10 \%$ & $10 \%$ \\
\hline
\end{tabular}

Legenda: Farinha de estufa (FE); Farinha de micro-ondas (FMO).

Fonte: Dados da pesquisa, 2019

Comparando a acidez nos dois tratamentos usados observou-se maiores índices na farinha obtida do produto do supermercado, o que indica uma maior vulnerabilidade à proliferação de micro-organismos.

Foi observado no sigma stat que a acidez na estufa para a farinha do filé apresentou $2,30 \pm 0,06^{*}$, e a farinha do resíduo $0,734 \pm 0,06$, as amostras apresentaram diferença entre si, sendo a maior acidez para a farinha do filé. $\mathrm{E}$ para o microondas a mesma ocorrência, farinha do filé $2,43 \pm 0,18^{*}$, e farinha do resíduo $0,683 \pm 0,07$, as amostras também apresentaram diferença entre si, sendo a maior acidez nas amostras da farinha do filé.

\subsection{Lipídios}

O teor de lipídios encontrados nas amostras de farinha de filé ficaram próximas aos resultados obtidos por Santos (2016). Já as farinhas obtidas por meio do resíduo do pescado apresentaram-se com valores elevados, o que pode ser devido ao tamanho e a quantidade de cabeças presentes na matéria-prima como também a quantidade de pele agregada ao esqueleto do pescado. 
A farinha obtida por meio da carne moída do produto oriundo do supermercado também apresentou altos valores de lipídios nos dois tratamentos térmicos (Tabela 5).

Tabela 5- Comparação do Teor de Lipídios.

\begin{tabular}{c|c|c}
\hline LIPÍDIOS (\%) & FE & FMO \\
\hline $\begin{array}{c}\text { PRODUTO } \\
\text { COMERCIAL }\end{array}$ & $\mathbf{6 9 , 9 2}$ & $\mathbf{2 5 , 0 3}$ \\
\hline FILÉ & $\mathbf{8 , 4 9}$ & $\mathbf{8 , 6 5}$ \\
\hline RESÍDUO & $\mathbf{2 3 , 1 0}$ & $\mathbf{2 1 , 0 4}$ \\
\hline FAROL,2019 & $4(\mathrm{mín})$ & \\
\hline
\end{tabular}

Legenda: Farinha de estufa (FE); Farinha de micro-ondas (FMO).

Fonte: Dados da pesquisa, 2019.

É importante salientar, que o alto teor de gordura no produto é de grande valia, considerando-se que a gordura de peixe é rica em ácidos graxos poliinsaturados os quais se destacam por apresentarem diversos efeitos benéficos à saúde humana, como diminuição dos riscos de doenças cardiovasculares e prevenção de câncer (VIDAL et al.,2011).

\section{5 $\mathrm{pH}$ e Aw}

Os dados obtidos nas análises de $\mathrm{pH}$ de todas as farinhas mantiveram-se em escala neutra (Tabela 7). E segundo Muzzolon et al. (2016) esses valores próximos à neutralidade favorecem o crescimento microbiano, sendo comum esse resultado, tendo em vista que, o pescado ser um alimento perecível. Os resultados de atividade de água de todas a farinhas aproximaram-se a 1 (Tabela 6). O que também para Muzzolon et al. (2016) esses valores condizem com os resultados de $\mathrm{pH}$, o que indica um excelente meio para o crescimento de micro-organismos.

Tabela 6- Comparação do Teor de Aw.

\begin{tabular}{c|c|c}
\hline Aw(\%) & FE & FMO \\
\hline $\begin{array}{c}\text { PRODUTO } \\
\text { COMERCIAL }\end{array}$ & $\mathbf{0 , 5 1}$ & $\mathbf{0 , 3 0}$ \\
\hline FILÉ & $\mathbf{0 , 5 0}$ & $\mathbf{0 , 5 7}$ \\
\hline RESIDUO & $\mathbf{0 , 2 0}$ & $\mathbf{0 , 2 5}$ \\
\hline
\end{tabular}

Legenda: Farinha de estufa (FE); Farinha de micro-ondas (FMO).

Fonte: Dados da pesquisa, 2019. 
Tabela 7- Comparação do Teor de pH.

\begin{tabular}{c|c|c}
\hline pH(\%) & FE & FMO \\
\hline $\begin{array}{c}\text { PRODUTO } \\
\text { COMERCIAL }\end{array}$ & $\mathbf{6 , 7 4}$ & $\mathbf{7 , 1 8}$ \\
\hline FILÉ & $\mathbf{6 , 9}$ & $\mathbf{6 , 7 3}$ \\
\hline RESIDUO & $\mathbf{7 , 2 3}$ & $\mathbf{7 , 2 6}$ \\
\hline
\end{tabular}

Legenda: Farinha de estufa (FE); Farinha de micro-ondas (FMO).

Fonte: Dados da pesquisa, 2019.

\subsection{PROTEÍNAS}

Para as análises de proteína bruta de todas as farinhas, os resultados obtidos foram satisfatórios quando comparado ao estudo realizado por Santos (2016). Os resultados da farinha de resíduo também foram superiores ao encontrado por Stevanato et al.(2007), ao avaliar a composição química dos resíduos da tilápia-do-nilo destinada à preparação de sopa. Resultados adquiridos por Vidal (2011) a partir de concentrado proteico de resíduos da filetagem de tilápia-donilo foi inferior à farinha de filé desta pesquisa (Tabela 8).

Tabela 8- Comparação do teor de Proteína Bruta.

\begin{tabular}{c|c|c}
\hline PROTEÍNA (\%) & FE & FMO \\
\hline $\begin{array}{c}\text { PRODUTO } \\
\text { COMERCIAL }\end{array}$ & $\mathbf{3 6 , 3 7}$ & $\mathbf{7 6 , 9 3}$ \\
\hline RESÍDUO & $\mathbf{4 3 , 6 6}$ & $\mathbf{4 3 , 1 3}$ \\
\hline FILÉ & $\mathbf{7 7 , 7 7}$ & $\mathbf{7 7 , 7}$ \\
\hline SANTOS,2016 & 20,04 & \\
\hline FAROL,2019 & $55(\mathrm{mín})$ & \\
\hline $\begin{array}{c}\text { STEVANATO et. al., } \\
\text { 2007 }\end{array}$ & 38,4 & \\
\hline
\end{tabular}

Legenda: farinha de estufa; farinha de microondas.

Fonte: Dados da pesquisa, 2019.

Comparando os resultados da análise de proteína bruta, pode-se observar que as farinhas de filé e do filé do produto comercial obtida por meio do Forno microondas apresentaram valores superiores ao determinado por FAROL (2019), que é de no mínimo 55\%, superando também os dados das pesquisas de STEVANATO et al. (2007) e SANTOS (2016). 


\subsection{Análise microbiológica}

$\mathrm{Na}$ análise microbiológica os resultados foram satisfatórios para as amostras de farinha de filé em estufa, corroborando também com os resultados obtidos por Santos; Willy (2014) que analisaram a farinha da cabeça da tilápia (Tabela 9). A ANVISA (2001) estabelece que para o pescado in natura a padronização microbiológica é de $10^{3}$ UFC g ${ }^{-1}$ para Estafilococos Coagulante Positiva, $10^{2}$ UFCC $g^{-1}$ no máximo para Coliforme a $45^{\circ} \mathrm{C}$ e para Salmonella sp. ausência para cada $25 \mathrm{~g}$. As farinhas passaram pelo mesmo processo de higienização, estando todas dentro dos padrões sanitários necessários.

Tabela 9- Resultado das análises microbiológicas.

\begin{tabular}{c|c}
\hline Contaminantes & FFE \\
\hline Mesófilos aeróbios & $7,5 \times 10^{4} \mathrm{UFC} / \mathrm{g}$ \\
\hline Enterobactérias totais & $2 \times 10^{2} \mathrm{UFC} / \mathrm{g}$ \\
\hline Coliformes termotolerantes & \\
\hline Salmonella & \\
\hline Estafilococos Coagulase \\
Positiva & $2,4 \times 10^{5} \mathrm{UFC} / \mathrm{g}$ \\
\hline Mesófilos totais & Legenda: Farinha de filé em estufa (FFE). \\
Fonte: Dados da pesquisa, 2019.
\end{tabular}

\section{Conclusões}

Após a análise física e química das farinhas, observou-se que as farinhas produzidas na estufa apresentaram valores de umidade acima do valor máximo preconizado para farinhas, porém com uma nova secagem da matéria prima inicial conseguiu-se obter valores satisfatórios;

Identifica-se que dentre os tratamentos térmicos utilizados, os resultados obtidos das farinhas aquecidas a partir do forno microondas chegaram mais próximos do adequado segundo a literatura utilizada; 
A farinha do resíduo apresentou resultados satisfatórios comparada às outras, entretanto, a farinha do filé também além dos bons resultados uma melhor coloração, mais adequada para a aceitação do público consumidor;

Observou-se que as farinhas se encontravam livres de contaminantes microbiológicos;

Por fim, pode-se concluir que o residuo é uma alternativa viável para seu reaproveitamento já que eles são continuamente descartados por várias vezes de forma inadequada no meio ambiente, podendo prejudicar a saúde dos seres vivos, e que o resíduo do pescado, assim como o filé, é uma excelente fonte de proteína, indicando como uma alternativa de incorporação dessa farinha na alimentação humana.

\section{Referências}

ANVISA- Agencia Nacional de Vigilância Sanitária. Resolução RDC n¹2, de 2 de janeiro de 2001. Aprova o regulamento técnico sobre padrões microbiológicos para alimentos. Ministério da Saúde, 2001.

FAO - FOOD AND AGRICULTURE ORGANIZATION (FAO). The State of World Fisheries and Aquaculture: contributing to food security and nutrition for all. Roma, FAO, 200 p, 2016.

FAROL, Indústria de Farinhas e Óleos de Origem Animal. 2019. Disponível em: < http://www.farol.ind.br/ produto/3/farinha-de-peixes > Acesso em fevereiro de 2019.

FELLOWS, Peter. Tecnologia do Processamento de Alimentos: princípios e prática. 2 ed. Porto Alegre: Artmed, 2006. 602 p.

FOLLMANN, Adriana ; CENTENARO, Andressa. Elaboração de bolo de laranja com diferentes concentrações de farinha de carcaça de tilápia do Nilo (Oreochromis niloticus). Trabalho de conclusão de curso. 59 p. 2013. Universidade Tecnológica Federal do Paraná - Câmpus Medianeira - Paraná.

GONÇALVES, Maria Júlia Santa Rosa. Aproveitamento Integral dos Resíduos da Filetagem de Tilápia e Avaliação do impacto econômico. Jaboticabal - SP. Agosto $-2009$. 
INSTITUTO ADOLFO LUTZ. Normas Analíticas do Instituto Adolfo Lutz. Métodos físico-químicos para análises de alimentos. $4^{\underline{a}}$ ed. (1 $1^{\text {a }}$ Edição digital), 2008. 1020 p.

MUZZOLON, Eloiza et. al. Caracterização físico-química e microbiológica de subprodutos da filetagem de tilápia para produção de almôndegas. Congresso Brasileiro de Ciências e Tecnologia de Alimentos. FAURGS-Gramado/RS. 2016.

OLIVEIRA-FILHO, Paulo Roberto Campagnoli; FRACALOSSI, Débora Machado. Coeficientes de digestibilidade aparente de ingredientes para juvenis de jundiá. Rev. Bras. Zootec, v. 35, p. 1581-1587, 2006.

SANTOS, Weslei Martins dos. Aproveitamento de subprodutos de resíduos de pesca para a produção de farinha. Trabalho de conclusão de curso. Pelotas, 2016.

SANTOS, Daiane Aparecida dos; WILLY, Katiane Aparecida. Incorporação diferentes concentrações de farinha de Tilápia do Nilo (Oreochromis niloticus) na elaboração de fishburguer. 2014. Trabalho de Conclusão de Curso. Universidade Tecnológica Federal do Paraná.

SILVA, Erica Lima da; MACEDO, Ana Beatriz Nascimento de; APOLINÁRIO, Marisa de Oliveira. PRODUÇÃo E CARACTERIZAÇÃo FÍSICA E QUÍMICA DE FARINHA DE TILÁPIA OREOCHROMIS NILOTICUS SUBMETIDA A DIFERENTES TRATAMENTOS TÉRMICOS. IN: Congresso Nacional de Pesquisa e Ensino em Ciências. 2019, Campina Grande IV anais Conapesc 2019.

STEVANATO, Flávia Braidotti et. al. Avaliação química e sensorial da farinha de resíduo de tilápias na forma de sopa. Ciência e Tecnologia de Alimentos, v. 27, n.3, p. 567-571, 2007.

SUCASAS, Lia Ferraz de Arruda; BORGHESI, Ricardo; OETTERER, Marília. Aproveitamento de resíduos reduz desperdícios e poluição ambiental. Visão Agrícola nำ11, 2012 pág. 150-151.

VIDAL, Juliana Maria Aderaldo et al. Concentrado protéico de resíduos da filetagem de tilápia-do-nilo (Oreochromis niloticus): caracterização físico-química e aceitação sensorial. Universidade Federal do Ceará, Fortaleza-CE. Revista Ciência Agronômica. 2011. 